\title{
COVID-19 Shows Us the Need to Plan Urban Green Spaces More Systemically for Urban Health and Wellbeing
}

\author{
Jieling Liu
}

\section{Key Messages}

In addition to the necessity and urgency for bottom-up climate actions, the significance of urban green spaces has been highlighted by the complex socio-economic impacts of COVID-19 on a global scale.

1. Sustainable urban development needs to go beyond segmented actions and to take a more systemic approach to urban planning, particularly that of green spaces.

2. Urban green spaces are particularly invaluable for those who cannot afford a spacious living environment, such as migrant workers and other vulnerable groups.

3. Urban green spaces should be treated as an invaluable common-pool resource for common health and wellbeing, i.e. one's use of green spaces should not reduce the availability of them for others, yet it is impossible and inadequate to exclude any residents from using green spaces regardless of their socio-economic status.

4. Policymakers should establish universal access to urban green space as the basic principle of urban planning, integrate climate modelling and public health monitoring into green space planning, and incorporate all societal actors in urban green space governance from planning to building to use and further to maintenance, for enhancing both social and environmental sustainability.

\footnotetext{
J. Liu (凶)

Climate Change and Sustainable Development Policies at Institute of

Social Sciences, University of Lisbon, Lisbon, Portugal

e-mail: jielingliu@ campus.ul.pt
} 


\section{Background}

Many countries and societies have approximated sustainable development through reducing carbon emissions, e.g. by applying green technology in transportation and in industry, reduction in deforestation and in plastic consumption. Yet, the current COVID-19 pandemic has (repeatedly, if we think of historical pandemics) made it clear to all of us that health is an important common denominator in any issues or risks urgently needed to be addressed today, from air pollution to plastic abuse, to income inequality, to the lack of essential live supporting infrastructure. An overview of human history tells us that health has always been the ultimate goal of all human beings and literally speaking all kinds of human collaborations we have come to devote ourselves to, including the current paradigm to pursue sustainable urban development, serve to achieve this goal. The global implications of COVID-19 on all sectors of socio-economic activities have demonstrated clearly that, much of the sustainable urban development practices are still either siloed, compartmentalized or too short-term, lacking synergy between one activity to another. Sustainable urban development needs to go way beyond these segmented actions and to take a more systemic approach to urban planning, particularly that of public and/or green spaces. The reasons are the following:

First, the irreversible urbanization trend and increasing urban density. With more than $50 \%$ of the world population living in cities, we are already living on an urban planet (Bai et al. 2018, p. 462). Yet, urban areas account roughly for only 3\% of the earth's surface (Ryan 2014; Liu et al. 2014). With increasing urbanization come several consequences. Urban areas where the majority of the population inhabit today are increasingly dense. The dense population implies increasing condensation of artificial infrastructure including transportation, housing, commercial, sanitation and other services; it also means a drastic reduction in ecological or green infrastructure such as parks, ecological corridors, wetlands, lawns, and other natural landscapes. For most of human history, populations had lived within small-scale and low-density social groups; urbanization is a trend unique to the past few centuries (Ryan 2019; Ritchie and Roser 2020).

The particular high mortality rate among the African American communities across US cities during COVID-19 has shown how dense living environments and the implied underprivileged socio-economic conditions are jeopardizing human health. African Americans have denser and older housing in many cities in the United States owing to the historical legacy of "redlining", a zoning policy made by the Federal Housing Administration to demarcate African American neighbourhoods initially to support affordable housing but ended up as a barrier to housing mortgages (Gross 2017; Vock et al. 2019). An example of the COVID-19 impact hitting these communities particularly hard: African Americans in Louisiana make up 70\% of the COVID-19 deaths in all known coronavirus patients in the state, while only representing about $32 \%$ of the population (Turk 2020). 
The second reason is the global interconnectivity. Ever since the old Silk Roads emerged beginning in the first century BC when Chinese luxury products started to appear in Rome, economic activities have begun to become global. Past industrial revolutions continued to interconnect raw materials, talents, services from all around the world. With the complex, hyperconnected globalized economic system today, one can hardly survive on local produce. The free-market economic system, based on which much of the urban areas have thrived, have used the convenience of globalized technology, international financial institutions and regional trade agreements to take advantage of abundant, cheap labour in the developing countries. The results have degraded the environmental quality in many emerging urban areas and offered pittances of economic benefits to labourers who are often referred to as urban migrants.

On the one hand, the high dependency of global interconnectivity for daily life in the urban era has drastically accelerated the spread of diseases such as COVID-19, compared to the pandemic of flu a century ago. On the other hand, increased air pollution, global climate change and the accompanying extreme weather events have increased the challenge of maintaining healthy lifestyles in dense and highly interconnected urban communities worldwide, weakening their ability to cope with epidemic diseases.

\section{Insights and Findings}

In addition to the necessity and urgency for bottom-up climate actions at the city level, the significance of urban green space resources has been further highlighted by the complex socio-economic impacts of COVID-19 on a global scale. As space in cities is increasingly claimed, marked, planned, and priced meticulously, public open spaces, such as parks, green corridors, lawns, are particularly invaluable spaces for the urban population, particularly for those who cannot afford a spacious living environment, such as migrant workers and other vulnerable groups. Open, walking spaces can contribute to enlarge distances between pedestrians, reducing the risk of transmission due to the dependency on public transportation, and furthermore, encourages walking and biking, which helps to maintain health. Google's global COVID-19 community mobility data shows that global mobility trends for park spaces during the quarantine period (mid-February-mid-May) decreased about $4.5 \%$ compared to pre-corona baseline; while mobility trends for retail and recreation spaces decreased around $22 \%$ and for workplaces decreased around $24 \%$ compared to baseline. These numbers highlighted the importance of urban green spaces. Sightings of nature during COVID-19 have seemed to help many people gain an alternative perspective to the one that had long been human-centric.

Urban green spaces in cities should be treated as an invaluable common-pool resource for our common health and wellbeing for two main reasons (Ostrom 2009). First, no one should be excluded from using urban green spaces for health and wellbeing purposes; technically speaking, it is also impossible to exclude any urban 
residents from benefiting from the multiple ecosystem services provided by urban green spaces, e.g. purified air and groundwater, and greater biodiversity. Second, urban green spaces in cities are limited due to the scarcity nature of urban land. That means one resident's use in existing green space will reduce the availability of that space for others; it also means one decision of land planning and land use for commercial or housing purposes will reduce the opportunities for additional green spaces. These two attributes determine that the current approaches of urban green space planning which rely on narrow indicators of success-diversification of tree species, coverage (certain size of green space per capita), aesthetics, etc., are insufficient. If a city wants to retain considerable urban green spaces for climate adaptation and make it accessible to everyone for wellbeing benefits, some form of integrative institutional arrangements for planning and governing urban green spaces elaborating all urban functions as a complex adaptive system must be introduced.

\section{Policy Recommendations}

Urban spatial planning and social policymaking share the role of distributing spaces more justly, taking into account that public spaces should first and foremost be able to serve all equally regardless of socio-economic status. Applying a systemic approach to plan and govern urban green space can help improve urban health and wellbeing. Policy recommendations for decision-makers at the city level include:

1. Establish universal access to urban green space as the basic principle of urban planning.

2. Integrate the modelling work of climate change impact and vulnerability and the monitoring system of public health into the planning for urban green spaces.

3. Incorporate all societal actors in the governance of urban green spaces from planning to building to use and to maintain, taking into account the ecology of plant species.

\section{References}

Bai X, Elmqvist T, Frantzeskaki N et al (2018) New integrated urban knowledge for the cities we want. In: Elmqvist T, Bai X, Frantzeskaki $\mathrm{N}$ et al (eds) Urban planet: knowledge towards sustainable cities. Cambridge University Press, Cambridge.

Gross T (2017) A 'forgotten history' of how the U.S. government segregated America. [202008-12]. https://www.npr.org/2017/05/03/526655831/a-forgotten-history-of-how-the-u-s-govern ment-segregated-america.

Liu Z, He C, Zhou Y et al (2014) How much of the world's land has been urbanized, really? A hierarchical framework for avoiding confusion. Landscape Ecol 29:5

Ostrom E (2009) Understanding institutional diversity. Princeton University Press, Princeton

Ritchie H, Roser M (2020) Urbanization. [2020-08-12]. https://ourworldindata.org/urbanization 
Ryan BJ (2014) Foreword: GEO—a globally integrated approach to urban monitoring. In: Weng Q (ed) Global urban monitoring and assessment through earth observation, remote sensing applications series. CRC Press.

Ryan C (2019) Civilized to death. Avid Reader Press/Simon \& Schuster, New York

Turk S (2020) Racial disparities in Louisiana's COVID-19 death rate reflect systemic problems. [2020-08-12]. https:/www.wwltv.com/article/news/health/coronavirus/racial-disparities-in-lou isianas-covid-19-death-rate-reflect-systemic-problems/289-bd36c4b1-1bdf-4d07-baad-6c3d20 $7172 \mathrm{f} 2$

Vock D, Brian C, Mike M (2019) How housing policies keep white neighborhoods so white (and black neighborhoods so black) — decades of local zoning regulations and land-use policies have kept racial segregation firmly rooted in place. [2020-08-12]. https:/www.governing.com/topics/ health-human-services/gov-segregation-housing.html 